\title{
Environmental Policy Attitudes: Issues, Geographical Scale, and Political Trust*
}

\author{
David M. Konisky, University of Missouri \\ Jeffrey Milyo, University of Missouri \\ Lilliard E. Richardson, Jr., University of Missouri
}

Objectives. This article examines environmental policy attitudes, focusing on the differences in preferences across issue type (i.e., pollution, resource preservation) and geographical scale (i.e., local, national, global). In addition, we study whether an individual's trust in government influences environmental policy attitudes. Methods. Analyzing data from the 2007 Cooperative Congressional Election Study, we estimate a series of OLS regression models to examine the public's environmental policy attitudes. Results. We find stronger public support for government action to address pollution issues than resources issues, and stronger support for local and national pollution abatement than dealing with global problems. We also find that Republicans and ideological conservatives are less likely to support further government effort to address the environment, and that more trusting individuals are more favorable to government action to address pollution and global issues. Conclusion. Environmental policy attitudes vary by the nature of the issue; however, political ideology and partisan affiliation are consistent predictors of preferences across issues, even when controlling for an individual's level of trust in government.

Since the onset of the modern environmental movement more than three decades ago, social scientists have actively examined public opinion on the environment. Recent research suggests that the U.S. public has persistently expressed concern about environmental problems (Dunlap, 2002; Guber, 2003). The General Social Survey, for example, has routinely asked the public whether the federal government is spending the right amount of money on improving and protecting the environment. For most of the past 30 years, majorities of the public (ranging from 50 percent to 60 percent) have responded that the federal government is spending too little. The apex

\footnotetext{
*Direct correspondence to David Konisky, Harry S Truman School of Public Affairs, 105 Middlebush Hall, University of Missouri, Columbia, MO 65211〈koniskyd@missouri.edu〉. The authors thank Robert Duffy, Andrew Kear, Tom Koontz, and the anonymous referees for helpful suggestions on earlier drafts of the article, as well as Tyler Schario for excellent research assistance. The University of Missouri Institute of Public Policy provided financial support for the project. Milyo also gratefully acknowledges financial support from the Hanna Family Fellowship at the Center for Applied Economics in the University of Kansas School of Business. All data and coding information are available on request.
} 
of support for more government spending came around 1990, likely a response to the Reagan Administration's retrenchment in environmental protection effort. Guber (2003) has shown a similar trend for other attitudinal measures, including those about the appropriate level of regulation and the degree that environmental protection is desired, even if it comes at the expense of jobs and economic growth.

One might reasonably infer from these attitudinal data that the public is generally supportive of government efforts to protect the environment, as large majorities are willing to support federal spending at the same or at increased levels to address environmental challenges. Because of the general nature of these types of questions, however, it is difficult to reach more than impressionistic conclusions about the environmental policy preferences of the U.S. public. For example, which environmental issues does the public think the government should spend the most time and money addressing? Does the public care more about local, national, or global issues? Does trust in government affect an individual's preferences for additional government action to address environmental problems?

To examine these questions, we analyze responses to the 2007 Cooperative Congressional Election Study (CCES). This survey included a battery of environmental questions asked of a 1,000-person nationally representative sample of U.S. adults. These questions enable us to compare public attitudes across a dozen environmental issues, ranging from those involving pollution to those involving natural resources, and varying in geographical scale from local to national to global. Although most of the extant literature focuses on measuring and explaining the general concept of overall environmental concern, we are interested in how policy attitudes vary across these dimensions. Moreover, when we evaluate the public's preferences for government intervention to address environmental issues, we can control for public trust in government, which allows us to disentangle attitudes about government from those about environmental policy.

To summarize our main findings, we find that public support for government action to address the environment differs across issue type and geographical scale. The public desires more government effort to address local and national pollution issues and less for global and natural resource problems. These findings underscore the value of studying policy attitudes with respect to specific issues, rather than focusing on single measures. In analyzing variation in these attitudes, we also find that they differ across segments of the population. The strongest predictors of environmental policy preferences are political attributes. Specifically, we find that Republicans and ideologically conservative individuals, controlling for their trust in government, are substantially less supportive of further government effort to address environmental issues.

The balance of the article proceeds as follows. Next, we briefly review the extant literature studying environmental attitudes. Subsequently, we describe the 2007 CCES and the questions we examine. We then analyze and 
discuss our findings regarding the public's environmental policy attitudes, focusing on the similarities and differences across the type and geographical scale of issues. We conclude with a discussion of the implications of our research.

\section{Measuring Environmental Policy Attitudes}

Most of the research studying public opinion about the environment has focused on defining and measuring what is generally referred to as "environmental concern." The concept of environmental concern has been defined in many ways. In a recent review of the literature, Dunlap and Jones (2002:485) defined it as "the degree to which people are aware of problems regarding the environment and support efforts to solve them and/or indicate a willingness to contribute personally to their solution." Scholars working in this area have grappled with difficult conceptual and measurement issues, such as dimensionality (e.g., Dunlap et al., 2000; Guber, 1996, 2003; Scott and Willits, 1994; Xiao and Dunlap, 2007) and the stability of opinions over time (e.g., Dunlap and Scarce, 1991; Dunlap, Xiao, and McCright, 2001; Guber, 2003). An important result from this research is that a single latent concept of environmental concern underlies a multitude of more specific attitudes about environmental issues.

Researchers have also attempted to identify the political and social determinants of environmental concern, focusing on a relatively standard set of individual-level attributes that might predict an individual's orientation toward the environment. Among the most consistent predictors of environmental concern are political ideology and party identification. Numerous studies have consistently demonstrated that Democrats and politically more liberal individuals tend to express stronger environmental attitudes than do Republicans and ideological conservatives (Carman, 1998; Dunlap, Xiao, and McCright, 2001; Guber, 2003; Kanagy, Humphrey, and Firebaugh, 1994; Klineberg, McKeever, and Rothenbach, 1998; Press, 2003; Uyeki and Holland, 2000; Van Liere and Dunlap, 1980). In addition, younger and better-educated segments of the U.S. public tend to express more pro-environmental attitudes (e.g., Carman, 1998; Kanagy, Humphrey, and Firebaugh, 1994; Klineberg, McKeever, and Rothenbach, 1998; Xiao and Dunlap, 2007).

Some research has also identified gender, race, and religious beliefs as important correlates of environmental concern. Regarding gender, several studies have found that women express more environmental concern than do men (Bord and O'Connor, 1997; Davidson and Freudenburg, 1996; Dietz, Kalof, and Stern, 2002; Mohai, 1992; Xiao and Dunlap, 2007),

\footnotetext{
${ }^{1}$ See Dunlap and Jones (2002) for a comprehensive review of this literature.
} 
whereas others have found inconclusive results (Blocker and Eckberg, 1989; Klineberg, McKeever, and Rothenbach, 1998). Studies estimating the relationship between race and environmental attitudes have had varied results. Early work found that African Americans tended to express weaker environmental concern (Hershey and Hill, 1977-1978) and prioritized other issues such as crime, education, and housing. More recent work has found few differences between African Americans and whites across a large number of environmental issues (Jones and Carter, 1994; Mohai and Bryant, 1998). Finally, there is some evidence that more religious individuals tend to be less concerned about environmental issues (Guth et al., 1995).

This article focuses on a different research question than examining the factors that shape concern for the environment. We study the distribution and determinants of public policy preferences for government action-what we refer to as environmental policy attitudes-to address different types of environmental issues. Specifically, we are interested in how support for government effort to address environmental issues varies by issue type and geographical scale, and the role that trust in government has in explaining this variation.

These questions are important for several reasons. First, there is disagreement in the literature on whether public attitudes about the environment are consistent across various types of issues (Klineberg, McKeever, and Rothenbach, 1998; Van Liere and Dunlap, 1981). In this study, we are particularly interested in comparing attitudes toward pollution and resource preservation issues. Some attention has been given to the differences in opinion across substantive issue types, but mostly as it relates to the environmental concern construct, not as a preference to understand (deHaven-Smith, 1988, 1991; Klineberg, McKeever, and Rothenbach, 1998; Mohai and Bryant, 1998 are exceptions). The possibility that public attitudes about environmental policy vary across different types of issues is an important question for the scholarly literature. Many studies have used a single item to characterize environmental preferences (e.g., Elliot et al., 1995; Kanagy, Humphrey, and Firebaugh, 1994; Johnson, Brace, and Arceneaux, 2005), but this is only appropriate to the extent to which the environment means the same thing to all people.

A second question of interest in the article is whether environmental policy attitudes differ according to the geographical scale of the issue. One might hypothesize that people prefer stronger policy measures directed toward more proximate issues. For example, the public may hold stronger conservation preferences for local natural areas than for tropical rain forests in other countries. Similarly, people may want additional action to address local air pollution problems that directly affect quality of life in their community, but care less about national-level air pollution that may not affect them at all. Several studies of U.S. public opinion have explicitly considered how attitudes vary across issues of different geographical scales (deHavenSmith, 1991; Dunlap, Gallup, and Gallup, 1993; Klineberg, McKeever, and 
Rothenbach, 1998; Mohai and Bryant, 1998; Murch, 1971), but most are either dated or rely on local or state-specific survey samples.

Finally, public trust in government may play an important role in understanding attitudes about government intervention to protect the environment. Trust in government has been shown to be correlated with policy preferences on a wide variety of issues (Hetherington, 2004), but to our knowledge it has not been considered in the context of environmental policy attitudes. This is important because survey questions often used to measure environmental policy attitudes typically ask a respondent about one's opinion on the desired level of government action (e.g., federal spending, effort) to address a particular environmental issue (Elliott, Seldon, and Regens, 1997; Guber, 2003; Carman, 1998). A concern with these questions is the possible conflating of attitudes about government and preferences about environmental protection (Klineberg, McKeever, and Rothenbach, 1998), the latter of which may be conditional on how much trust the individual has in government. We examine the role of public trust in government, as well as issue type and geographical scale in the analyses to follow.

\section{Survey Data}

To analyze the environmental policy attitudes of the public, we examine survey data from the 2007 CCES. The overall CCES study included a sample of 10,000 persons conducted through the collaborative efforts of a consortium of universities. Each university team designed its own questionnaire, which was administered to a 1,000-person subsample. Survey participants also responded to a set of common questions, which were asked of the entire 10,000-person sample. The 2007 CCES survey was administered in November 2007 by Polimetrix, an Internet survey firm located in Palo Alto, California. ${ }^{2}$ Polimetrix uses a national matched-random sampling method in which participants are selected to reflect the national adult population (Rivers, n.d.).

The survey instrument for this analysis included a battery of questions about environmental issues we designed as part of the 2007 CCES. Specifically, respondents were asked to think about the role of government in addressing 12 environmental issues. ${ }^{3}$ The precise wording of the question was as follows: "Thinking about Environmental Issue X, how much effort do you think the government should put into addressing this issue?" The response categories were: "A lot less," "A little bit less," "About the same," "A little bit more," or "A lot more." As presented in Figure 1, the environ-

\footnotetext{
${ }^{2}$ More information about the CCES project can be found at $\langle$ http://web.mit.edu/polisci/ portl/cces/index.html $\rangle$.

${ }^{3}$ Gallup periodically asks about many of these issues in its surveys on environmental opinion, usually in the context of how much individuals personally worry about each issue.
} 
FIGURE 1

Environmental Issues in the Survey.

\begin{tabular}{|l|l|l|}
\hline \multirow{2}{*}{ Geographical Scale } & Pollution & Resources \\
\hline \multirow{5}{*}{ National } & $\begin{array}{l}\text { Protecting community drinking } \\
\text { water } \\
\text { Reducing urban air pollution } \\
\text { issues like smog }\end{array}$ & $\begin{array}{l}\text { Preserving natural areas near } \\
\text { where I live } \\
\text { Managing urban sprawl }\end{array}$ \\
\hline \multirow{5}{*}{ Global } & $\begin{array}{l}\text { Reducing pollution of the nation's } \\
\text { rivers, lakes, and ecosystems } \\
\text { Reducing national air pollution } \\
\text { problems like acid rain }\end{array}$ & $\begin{array}{l}\text { Preserving national forests and } \\
\text { other federally protected areas } \\
\text { Managing national parks }\end{array}$ \\
\hline $\begin{array}{l}\text { Reducing emissions that } \\
\text { contribute to global warming } \\
\text { Preventing damage to the earth's } \\
\text { ozone layer }\end{array}$ & $\begin{array}{l}\text { Preventing loss of the world's } \\
\text { tropical rain forest } \\
\text { Protecting the world's plant and } \\
\text { animal species from extinction }\end{array}$ \\
\hline
\end{tabular}

mental issues of interest were deliberately chosen to provide variation on two dimensions: issue type and geographical scale. In terms of issue types, the dozen environmental problems in the survey were evenly divided between pollution issues and what we will term "resource issues," by which we mean protection of natural and biological resources. With respect to geographical scale, four questions were asked about local issues, four about national issues, and four about global issues. The issues were each described with precise geographical referents to eliminate ambiguity about the scale of each environmental problem (Xiao and Dunlap, 2007). Within each of the four issues asked for each geographical scale, two were pollution questions and two were resource questions.

There are several other important design elements of the 2007 CCES battery of environmental questions to note. First, the series of questions was specifically designed to minimize the conflating of attitudes about government, federal spending, and environmental protection. The survey asked about respondents' preferred level of government effort, without specifying spending. The purpose here was to de-couple attitudes about spending from those about environmental protection needs. In addition, the survey asked respondents about their level of trust in government. Specifically, respondents were asked to characterize their trust in local, state, and federal government. These questions enable differentiation across different levels of 
government, and provide a control variable to use to disentangle the public's attitude about environmental policy from its attitude about government in general.

Second, the survey used consistent wording for the 12 issues, so that the only factor varying in each question was the issue itself. Some past survey research on environmental issues has suffered from problems in which some questions are asked in a pro-environmental direction, whereas others are asked in what might be characterized as an anti-environmental direction (Dunlap and Jones, 2002). Last, in the administration of the survey, the 12 issues were asked about in a random order to minimize bias from question ordering effects.

\section{Survey Results}

In this section of the article, we turn to the survey results. We first compare public attitudes across the 12 environmental issues to determine whether and how attitudes differ across issue type and geographical scale. Second, we estimate a series of regression models to examine whether and how the determinants of environmental policy attitudes diverge across these dimensions.

\section{Describing Public Attitudes on the Environment}

The battery of environmental questions in the 2007 CCES enables a direct comparison of the public's policy attitudes on 12 distinct environmental issues. As a first step in understanding these attitudes, we present the full distribution of responses in Table 1. The respondents express strong support for increased government effort across the 12 issues. Large majorities support either a lot more or a little bit more government effort to address all the issues, and for half the issues, a third or more of the sample indicates that they want the government to put forth a lot more effort. The percentage of the public expressing a desire for the government to reduce its environmental protection effort is strikingly small, representing less than 10 percent of the sample for each of the nonglobal-scale issues.

In Table 1, we rank the environmental issues by the mean level of response for each, where "A lot more" is coded 2, "A little bit more" is coded 1 , "About the same" is coded 0, "A little bit less" is coded - 1, and "A lot less" is coded -2 . Positive values therefore indicate a preference for more government effort to address the issue. The means and standard deviations are presented in the last column of the table. Protecting community drinking water is the issue with the most public support, and it is followed in order by reducing pollution in U.S. rivers, lakes, and ecosystems, and reducing urban air pollution. The least support is for preserving natural areas 


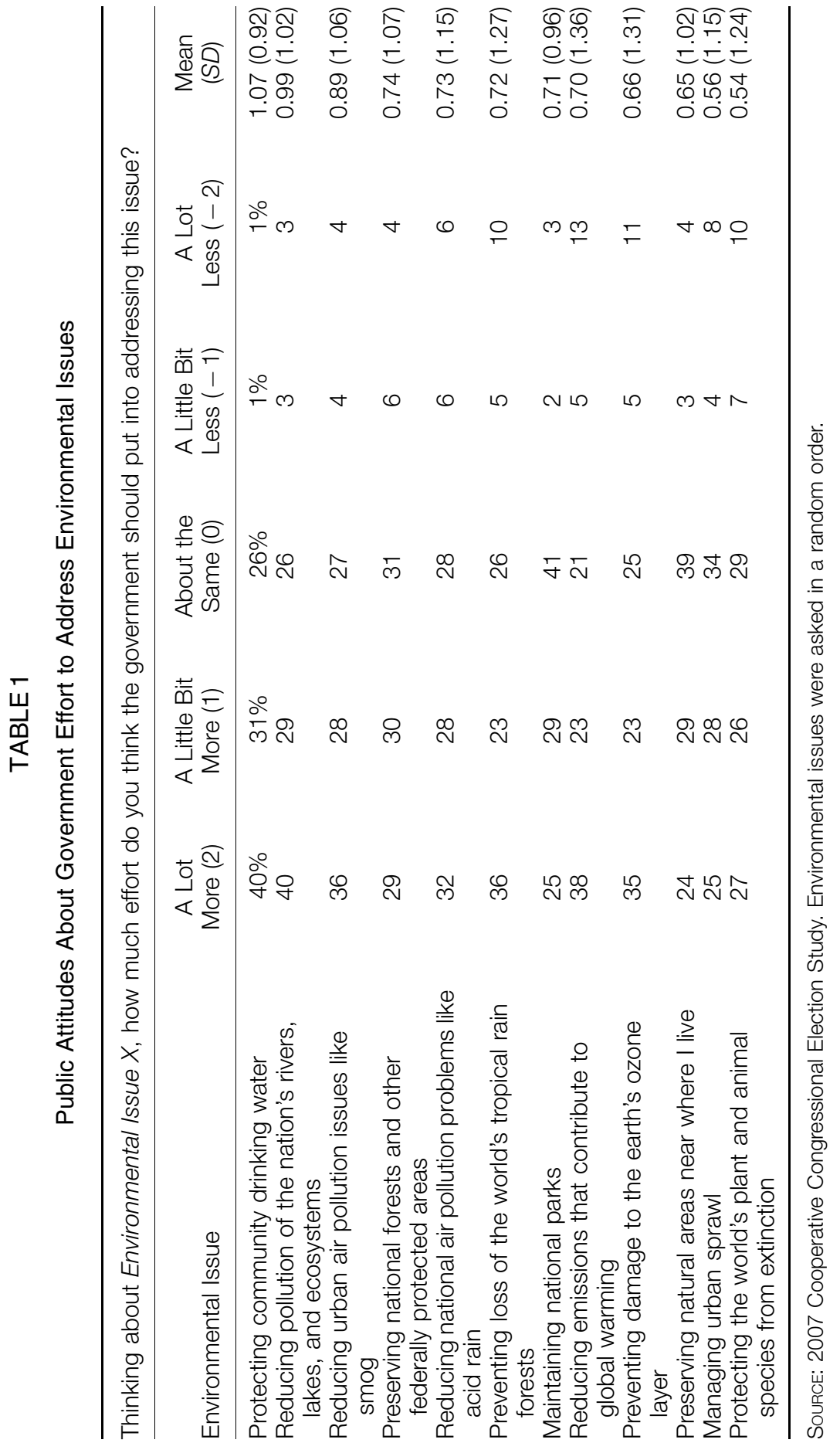


near where the respondent resides, managing urban sprawl, and protecting biodiversity.

There are several patterns worth noting in the responses to these 12 items. First, the U.S. public is particularly concerned about local and national pollution issues. The top three issues (and four of the top five) for which the public wants government to take action are pollution issues at the local or national level. The next group of issues according to the mean-based rankings consists of three national and three global problems (means range from 0.65 to 0.74 ). Included in this middle group is global warming, which the public places as the eighth most important issue. This is somewhat surprising given the high level of media attention that global warming has recently received, but it may simply reflect disagreement about the severity (or existence) of climate change. Last, at the bottom of the rankings are three resource preservation issues, including those that can be categorized as global-level or local-level problems. Collectively, these trends in the data suggest attitudinal differences along an issue type dimension-pollution compared to resources-and a geographical-scale dimension-national and local compared to global.

\section{Explaining Public Attitudes on the Environment}

To further examine public preferences for government action to protect the environment, we examine the determinants of public attitudes. Of particular interest is how commonly found correlates of overall environmental concern explain policy attitudes for environmental issues in general, and for pollution and resource preservation issues and for issues at varying geographical scale, in particular.

To examine these questions, we constructed several scales, which serve as the dependent variables in the regression analyses that follow. First, we use the responses to each of the 12 questions to construct a single index. The scale ranges from -24 to 24 , where higher values represent greater support for additional government action to address the environmental issues. The mean value on the scale is 8.9 , with a standard deviation of 11.4 . Table 2 presents the descriptive statistics for this scale and the others we describe below. The Cronbach alpha indicates a reliability coefficient of 0.96 for the responses, indicating that the responses to the 12 questions fit together very well on a single scale. Moreover, the scale correlates at 0.61 with responses given by the participants to a question asking them about their overall level of concern with the environment. ${ }^{4}$

\footnotetext{
${ }^{4}$ The specific question was as follows: How would you characterize your overall level of concern for the environment? Would you say you are not concerned, a little concerned, somewhat concerned, very concerned, or haven't you thought much about this? Thirty-eight percent of the respondents said they were "very concerned," 32 percent were "somewhat concerned," 21 percent were "a little concerned," 6 percent were "not concerned," and about
} 
TABLE 2

Environmental Policy Attitudes Scales

\begin{tabular}{lcccc}
\hline Issue Scales & Mean & SD & Minimum & Maximum \\
\hline All & 8.9 & 11.4 & -24 & 24 \\
Pollution & 5.0 & 6.0 & -12 & 12 \\
Resources & 3.9 & 5.7 & -12 & 12 \\
Local & 3.2 & 3.5 & -8 & 8 \\
National & 3.2 & 3.7 & -8 & 8 \\
Global & 2.6 & 4.7 & -8 & 8 \\
\hline
\end{tabular}

SOURCE: 2007 Cooperative Congressional Election Study.

We create analogous scales for pollution issues and resource issues, using the responses for each relevant set of questions. Because each scale is based on responses to six questions, the scale ranges from -12 to 12 . The mean level of support is 5.0 for the pollution scale and 3.9 for the resources scale, which reflects the stronger preferences for government action to address pollution issues than resource preservation issues. An explanation for this difference may be that pollution problems tap into more consensual values about human health, while there is less of a nationwide preservation ethic. We also construct a scale for each of the three geographical levels of interest-local, national, and global. ${ }^{5}$ Each scale is comprised of four survey items, ranging from -8 to 8 , with a mean of 3.2 for the set of local and national issues, and 2.6 for global issues. In addition to the lower mean for the global issues, there is also a larger standard deviation, which reflects the higher degree of disagreement about the desired level of government action to address global-level issues. The Cronbach alpha statistic for each of the scales is at least 0.87 , providing justification for combining the items in each into a single index. ${ }^{6}$ It is possible that the high correlation in the responses reflects consistency in views about government intervention as much as about the environment. We explore this possibility in the analyses that follow.

3 percent said they "have not thought much about this issue." The correlations between the other scales described below and respondents' overall concern for the environment range from 0.56 to 0.62 , suggesting consistency across the measures of environmental policy attitudes.

${ }^{5}$ These scales, as well as the issue scales described above, are constructed based on content validity, rather than a formal factor analysis. Because the items vary both substantively (pollution vs. resources) and in geographical scale (local vs. national vs. global), it would be difficult to disentangle the items with a factor analysis. The correlation between the pollution and resources scale is 0.89 , and the correlations among the geographical scales range from 0.85 to 0.88 .

${ }^{6}$ The Cronbach alpha statistic for the pollution and natural resources scales is 0.94 and 0.92 , respectively. For the local, national, and global scales, the Cronbach alpha statistic is $0.87,0.90$, and 0.93 , respectively. 


\section{Estimating Models of Environmental Policy Attitudes}

We estimate regression models to test a set of determinants of environmental policy attitudes against each of the scales. These models enable an initial analysis of how perceptions differ (or coincide) among different segments of the population for different groupings of the environmental issues. We use a set of explanatory variables often employed to predict environmental attitudes, including age (in years), gender (female coded 1, male coded 0 ), race (minorities coded 1 , whites coded 0 ), education (6-point scale ranging from no high school to a postgraduate degree), church attendance (4-point scale ranging from almost never to once a week or more), urban residence (individuals living in an urban county coded 1, those living in a rural county coded 0 ), political ideology (5-point scale ranging from very liberal to very conservative), and party identification (a Republican indicator, an independent or other party indicator, with Democrat as the excluded category). ${ }^{7}$

We also include a variable representing the respondent's level of trust in government. The trust in government measure is a scale ranging from 0 to 9 , constructed by adding the responses to three questions that asked the respondents to characterize their level of trust in local, state, and federal government (each question is a 4-point scale ranging from hardly ever to just about always). ${ }^{8}$ We use the respondent's level of trust in government to capture his or her general confidence in government so that we can disentangle the respondent's environmental policy attitudes from his or her perceptions about government in general.

We present the results from the first set of regressions in Table 3. The OLS regression coefficients displayed in the first column are for the model using the scale derived from the responses to all 12 environmental issues in the survey. The strongest predictors of support for government action to address these issues are political ideology and party identification. The coefficient of -5.4 on the political ideology variable suggests that, for each point increase on the scale (from liberal to conservative), there is a movement of about five points, or nearly half a standard deviation, on the environmental issues scale toward less government intervention. There is a similar size effect for Republicans relative to Democrats. Individuals expressing more trust in government are more likely to support additional government action to address environmental issues, although the coefficient is only marginally statistically significant. A two standard deviation change

\footnotetext{
${ }^{7}$ The 2007 CCES asked a question about household income, but we exclude it from the regressions because nearly 15 percent of the respondents did not provide a response and we did not want to drop these individuals from the sample. When we include income as a covariate, the coefficient does not attain statistical significance.

${ }^{8}$ The Cronbach alpha indicates a reliability coefficient of 0.75 for the responses.
} 
TABLE 3

Determinants of Environmental Policy Attitudes, by Issue Type

\begin{tabular}{lccc}
\hline & $\begin{array}{c}\text { All } \\
\text { Issues } \\
(1)\end{array}$ & $\begin{array}{c}\text { Pollution } \\
\text { Issues } \\
(2)\end{array}$ & $\begin{array}{c}\text { Resources } \\
\text { Issues } \\
(3)\end{array}$ \\
\hline Age & $0.06^{*}$ & $0.02^{\dagger}$ & $0.03^{*}$ \\
Female & $(0.03)$ & $(0.01)$ & $(0.01)$ \\
Minority & $1.26^{\dagger}$ & $0.83^{*}$ & 0.39 \\
Education & $(0.66)$ & $(0.35)$ & $(0.35)$ \\
Church attendance & -0.27 & -0.20 & -0.29 \\
Urban residence & $(0.92)$ & $(0.47)$ & $(0.47)$ \\
Political ideology & 0.06 & 0.00 & 0.04 \\
Republican & $(0.24)$ & $(0.12)$ & $(0.12)$ \\
Independent or other party & -0.11 & -0.07 & -0.19 \\
Trust in government & $(0.29)$ & $(0.15)$ & $(0.15)$ \\
Constant & -1.51 & -0.77 & -0.68 \\
& $(0.94)$ & $(0.49)$ & $(0.48)$ \\
Observations & $-5.43^{* *}$ & $-2.78 * *$ & $-2.59 * *$ \\
$R^{2}$ & $(0.41)$ & $(0.21)$ & $(0.21)$ \\
& $-4.86^{* *}$ & $-2.92^{* *}$ & $-2.17 * *$ \\
\hline
\end{tabular}

Cells contain OLS regression coefficients with standard errors in parentheses. Significance levels: ${ }^{\dagger} p>0.10 ; * p>0.05 ; * * p>0.01$.

Scale for all issues ranges from -24 to 24 , and for pollution issues and resource issues from -12 to 12 .

in the trust variable would represent about a one point difference on the scale. Counter to much of the existing literature, age is positively associated with the environmental issues scale, but the effect is small; a decade difference in age accounts for only half a point on the scale. ${ }^{9}$ Last, the estimates provide some evidence that women are more supportive of government action to address the environment.

The next two columns of Table 3 show the results using the separate scales for pollution and resource issues. Looking across the coefficients, there

${ }^{9} \mathrm{~A}$ possible explanation for this finding regarding age is that there is a cohort effect. Older survey respondents in 2007 are a different cohort of individuals than those who participated in the surveys studied in much of the existing literature. For example, "Baby Boomers" may have different environmental attitudes than the "World War II generation" due to different experiences at the age when they formulated their opinions about the environment. 
are both interesting similarities and differences. Political ideology and party identification remain the strongest predictors for each set of issues. Politically conservative respondents and Republicans, on average, favor less government action on the environment regardless of the issue type. The size of the effect for pollution issues is similar to the resource preservation values. Age is positively associated with each scale, suggesting, again, that older adults are more favorable to governmental effort to address environmental problems.

There are also a couple of notable differences between the models. Trust in government has a statistically significant positive effect on public attitudes about government action to address pollution issues, but there is no such association in the resources model. Gender differences are also present. Women are more supportive of government intervention to deal with pollution issues, but we do not observe differences regarding resource issues. These varying results across the models suggest some subtle issue type differences in environmental policy attitudes.

The next set of models we estimate examine the determinants of attitudes for the environmental issues grouped according to their geographical scale. These results are presented in Table 4. One important difference in these models is in the way we measure trust in government. Here, we focus on an individual's trust in the most relevant level of government for each set of issues. Specifically, we use trust in local government for the set of local issues, and trust in the federal government for the set of national and global issues.

Once again and consistent with studies of general environmental concern, the most robust relationships we find across all three levels of geographical scale are between environmental policy attitudes and political ideology and party identification. Irrespective of the geographical scale, ideologically conservative individuals are less likely to support further government action, even after controlling for their level of trust in government. For each point increase on the political ideology scale from liberal to conservative, there is a movement from one to two points lower on the environmental issues scale. The negative association between Republicans and support for government action remains large and statistically significant in each model, with a particularly large effect in the global issues model. The size of the effect for global issues, in fact, is about twice that for local issues, a subject we return to in the discussion below. Independents are also less favorable than Democrats about government action to deal with global environmental problems.

Demographic variables again perform rather poorly overall. Older adults are more favorable to government effort to address local- and national-scale problems than are younger people, but the size of the effect is modest. Women are also more supportive of government action to deal with localand global-scale issues than are men, but we do not see gender difference for 
TABLE 4

Determinants of Environmental Policy Attitudes, by Geographical Scale

\begin{tabular}{lccc}
\hline & $\begin{array}{c}\text { Local } \\
\text { Issues } \\
(1)\end{array}$ & $\begin{array}{c}\text { National } \\
\text { Issues }\end{array}$ & $\begin{array}{c}\text { Global } \\
\text { Issues }\end{array}$ \\
& $0.02^{\dagger}$ & $(2)$ & $(3)$ \\
\hline Age & $(0.01)$ & $0.02 * *$ & 0.01 \\
Female & $0.41^{\dagger}$ & $(0.01)$ & $(0.01)$ \\
& $(0.22)$ & 0.27 & $0.51^{\dagger}$ \\
Minority & -0.13 & $(0.22)$ & $(0.27)$ \\
Education & $(0.30)$ & -0.24 & 0.01 \\
& -0.04 & $(0.29)$ & $(0.37)$ \\
Church attendance & $(0.08)$ & 0.08 & -0.06 \\
& 0.12 & $(0.08)$ & $(0.10)$ \\
Urban residence & $(0.09)$ & -0.04 & -0.14 \\
& -0.644 & $-0.09)$ & $(0.12)$ \\
Political ideology & $(0.30)$ & $(0.30)$ & -0.62 \\
& $-1.52 * *$ & $-1.62 * *$ & $(0.38)$ \\
Republican & $(0.13)$ & $(0.13)$ & $-2.29 * *$ \\
& $-1.21 * *$ & $-1.55^{* *}$ & $(0.17)$ \\
Independent or other party & $(0.34)$ & $(0.35)$ & $2.25^{* *}$ \\
& -0.22 & -0.29 & $(0.43)$ \\
Trust in government & $(0.28)$ & $(0.28)$ & $-0.74 *$ \\
& -0.09 & 0.10 & $(0.35)$ \\
Constant & $(0.14)$ & $(0.15)$ & $0.17^{*}$ \\
& $7.68 * *$ & $7.84 * *$ & $(0.08)$ \\
Observations & $(0.75)$ & $(0.73)$ & $10.7 * *$ \\
$R^{2}$ & 886 & 901 & $(0.93)$ \\
\hline
\end{tabular}

Cells contain OLS regression coefficients with standard errors in parentheses. Significance levels: ${ }^{\dagger} p>0.10 ; * p>0.05 ; * * p>0.01$. Scales range from -8 to 8 .

national-scale problems. Finally, an individual's trust in government is a significant predictor only for global issues; respondents with higher levels of confidence in government are more likely to support government action to address issues such as climate change, ozone depletion, and the protection of biodiversity.

The weak relationships between many of the demographic variables and environmental policy attitudes conflicts with much of the research that has explored the determinants of environmental attitudes. One possible explanation is that the demographic characteristics are operating through the political variables. To examine this possibility, we estimated a series of regressions (not reported) without the political variables included in the model, and found positive correlations between women, minorities, and better-educated individuals and support for government efforts to address environmental issues, and a negative association with frequent churchgoers. 
These demographics, however, explain less than 10 percent of the variance in the environmental issues scales. 10

To further test the robustness of our findings, we also estimated these models with an additional control variable to account for the respondents' assessments of environmental quality. It is likely that people's attitudes about the appropriateness of government intervention are related to these assessments. The 2007 CCES included questions asking respondents to provide their assessment of local, national, and global environmental quality. ${ }^{11}$ We did not include this response as a control variable in the models described above due to endogeneity concerns. ${ }^{12}$ When reestimating the models above including the respondent's assessment of environmental quality, the core results summarized above are largely the same. Political ideology and party identification remain the strongest predictors of environmental policy attitudes. Across the three models, the coefficient for the environmental quality assessment variables were always negative and statistically significant, indicating that those individuals viewing environmental quality as poor are more supportive of government action to address it.

\section{Thinking Local, But Not Global?}

Analyzing the determinants of environmental policy attitudes toward the different groupings of issues provides the simplest way to examine how individual-level correlates may differ across the issues. The analysis thus far, however, does not explain the discernible dropoff in support from government action to address local pollution to the lower level of support for addressing global pollution issues. Recall that local pollution issues topped the issues of most concern to the public, while global pollution issuesglobal warming and ozone depletion-were in the middle of the pack.

\footnotetext{
${ }^{10} \mathrm{We}$ also estimated regressions with the political ideology and party identification as dependent variables and the demographics as the covariates. Consistent with expectations, women, minorities, and better-educated individuals all tended to be ideologically more liberal and more likely to affiliate with the Democratic Party, while men, frequent churchgoers, and those living in rural areas tended to be more ideologically conservative and more likely to identify with the Republican Party. These demographics explain about 20 percent of the variance of these variables.

${ }^{11}$ The first question reads: Overall, how would you rate the quality of the global environment? Would you say that it is very good, fairly good, fairly bad, or very bad? This was followed by a question about the quality of the environment in the United States and in the respondent's local community.

${ }^{12}$ How an individual perceives environmental quality might affect how much effort he or she thinks the government should put forth to address an issue, but attitudes about how much government intervention the individual thinks is necessary to address an environmental issue may also predict his or her assessment of environmental quality.
} 
Although one might infer from this pattern of responses that people have stronger preferences for government action to address local rather than global issues, local resource preservation issues also came in at the very bottom of the rankings.

To determine which segments of the population account for the decline in support for global pollution issues relative to that for local pollution issues, we consider two additional dependent variables. First, we create a dichotomous measure coded 1 for survey respondents who indicate a desire for more or the same amount of government action to address local pollution issues and a desire for less government action to address global warming (114 respondents). All other respondents are coded 0 . We construct an analogous variable for ozone depletion (107 respondents). In each case, we are holding the issue type constant (i.e., pollution), while the geographical scale of the issue varies.

We estimate a series of logistic regression models, using the same set of explanatory variables as before. The first column of Table 5 presents the results (odds ratios) for the case of a dropoff in support for global warming. These estimates suggest that a Republican is about five times more likely than a Democrat to exhibit a dropoff. Independents and other politically affiliated individuals are nearly four times more likely. For each point on the political ideology scale toward conservative, individuals are about twice as likely to drop off in their support for government action as the policy issue changed from local pollution to global pollution. Frequent churchgoers, older respondents, nonminorities, and men are more likely to drop off in their support. The findings for ozone depletion are similar with regard to party identification and political ideology, although the effects are somewhat smaller for party affiliation. In addition, more highly educated respondents are more likely to express a drop off in support for government action to address ozone depletion. ${ }^{13}$

\section{Conclusion}

The results from the 2007 CCES indicate that the public overwhelmingly supports additional government effort to address a myriad of environmental issues, but that the strength of this support varies according to the type and geographical scale of the issue. In general, we find the public more favorable to government action addressing local and national pollution issues, and less for global and natural resource problems. Despite these differences, our

\footnotetext{
${ }^{13}$ We also estimated models to identify the correlates of individuals that drop off in support for global pollution issues from national pollution issues. The findings are similar to the case of dropoff from local pollution issues.
} 
TABLE 5

Explaining Dropoff in Public Support for Government Action

\begin{tabular}{lcc}
\hline & \multicolumn{2}{c}{ High Support for Local Pollution Compared to } \\
\cline { 2 - 3 } & $\begin{array}{c}\text { Low Support for Global } \\
\text { Warming (1) }\end{array}$ & $\begin{array}{c}\text { Low Support for Ozone } \\
\text { Depletion (2) }\end{array}$ \\
\hline Age & $1.01^{\dagger}$ & $1.01^{* *}$ \\
Female & $(0.01)$ & $(0.008)$ \\
Minority & $0.54^{* *}$ & 0.78 \\
& $(0.13)$ & $(0.18)$ \\
Education & $0.51^{\dagger}$ & 0.67 \\
Church attendance & $(0.20)$ & $(0.24)$ \\
& 1.06 & $1.14^{\dagger}$ \\
Urban residence & $(0.08)$ & $(0.09)$ \\
& $1.23^{*}$ & 1.10 \\
Political ideology & $(0.11)$ & $(0.10)$ \\
Republican & 1.10 & 1.08 \\
Independent or other & $(0.31)$ & $(0.31)$ \\
party & $2.23^{* *}$ & $2.26 * *$ \\
Trust in government & $(0.34)$ & $(0.35)$ \\
Observations & $4.93^{* *}$ & $2.91 *$ \\
Pseudo $R^{2}$ & $(2.75)$ & $(1.32)$ \\
Model $\chi^{2}$ (probability) & $3.95^{*}$ & 2.01 \\
& $(2.16)$ & $(0.89)$ \\
& 1.03 & 1.06 \\
& $(0.16)$ & $(0.16)$ \\
& 913 & 913 \\
& 0.17 & 0.14 \\
& 116.1 & 89.5 \\
& 0.000 & 0.000 \\
\hline
\end{tabular}

Cells contain odds ratios from logistic regression, with standard errors in parentheses. Significance levels: ${ }^{\dagger} p>0.10 ; * p>0.05 ; * * p>0.01$.

regression results suggest a common set of predictors across environmental issues. We find a consistently strong relationship between political ideology and party identification and environmental policy attitudes. Across issue type and geographical scale, ideologically conservative individuals and Republicans expressed considerably less enthusiasm for further government action on the environment. These ideological and partisan relationships exist even when controlling for an individual's level of trust in government, suggesting that the findings have more to do with attitudes about the environment than just general attitudes about government. These findings reaffirm decades of research showing that political ideology and party identification are important correlates of environmental attitudes (Dunlap, Xiao, and McCright, 2001). Although we do find that age and gender are relatively consistent correlates of environmental policy attitudes, overall 
personal demographic attributes are much weaker predictors than are political attributes.

A strength of the set of questions included in the 2007 CCES is that they enable the direct comparison of public attitudes across a wide set of environmental issues. The general nature of the questions, however, also has some limitations. The question design did not require respondents to consider tradeoffs. That is, while support for government action to increase environmental protection is clearly high among the public, it is not possible to infer what the public might be willing (or unwilling) to exchange for increased government effort toward improving environmental protection. Examination of attitudes toward different types and geographical scales of environmental issues that directly tap into these tradeoffs is an important area for future research.

\section{REFERENCES}

Blocker, T. Jean, and Douglas Lee Eckberg. 1989. “Environmental Issues as Women's Issues: General Concerns and Local Hazards." Social Science Quarterly 70:586-93.

Bord, Richard J., and James O'Connor. 1997. "The Gender Gap in Environmental Attitudes: The Case of Perceived Vulnerability to Risk." Social Science Quarterly 78: $830-40$.

Carman, Christopher Jan. 1998. "Dimensions of Environmental Policy Support in the United States.” Social Science Quarterly 79(4):717-33.

Davidson, Debra J., and William R. Freudenburg. 1996. "Gender and Environmental Risk Concerns: A Review and Analysis of Available Research." Environment and Behavior 28(30):302-39.

deHaven-Smith, Lance. 1988. "Environmental Belief Systems: Public Opinion Toward Land Use Regulation in Florida." Environment and Behavior 20(2):176-99.

. 1991. Environmental Concern in Florida and the Nation. Gainesville, FL: University
of Florida Press.

Dietz, Thomas, Linda Kalof, and Paul C. Stern. 2002. "Gender, Values, and Environmentalism.” Social Science Quarterly 83(1):353-64.

Dunlap, Riley E. 2002. “An Enduring Concern.” Public Perspectives September/October:10_ 14.

Dunlap, Riley E., George H. Jr. Gallup, and Alec M. Gallup. 1993. "Of Global Concern: Results of the Health of the Planet Survey." Environment 35:7-15, 33-39.

Dunlap, Riley E., and Robert Emmet Jones. 2002. "Environmental Concern: Conceptual and Measurement Issues." In Riley E. Dunlap and William Michelson, eds., Handbook of Environmental Sociology. Westport, CT: Greenwood Press.

Dunlap, Riley E., and Rik Scarce. 1991. "Poll Trends: Environmental Problems and Protection." Public Opinion Quarterly 55(4):651-72.

Dunlap, Riley E., Kent D. Van Liere, Angela G. Mertig, and Robert Emmet Jones. 2000. "Measuring Endorsement of the New Ecological Paradigm: A Revised NEP Scale." Journal of Social Issues 56(3):425-42. 
Dunlap, Riley E., Chenyang Xiao, and Aaron M. McCright. 2001. "Politics and Environment in America: Partisan and Ideological Cleavages in Public Support for Environmentalism." Environmental Politics 10(4):23-48.

Elliott, Euel, James L. Regens, and Barry J. Seldon. 1995. "Exploring Variation in Public Support for Environmental Protection.” Social Science Quarterly 76:41-52.

Elliott, Euel, Barry J. Seldon, and James L. Regens. 1997. "Political and Economic Determinants of Individuals' Support for Environmental Spending." Journal of Environmental Management 51:15-27.

Guber, Deborah Lynn. 1996. "Environmental Concern and the Dimensionality Problem: A New Approach to an Old Predicament." Social Science Quarterly 77(3):644-62.

2003. The Grassroots of a Green Revolution: Polling America on the Environment. Cambridge, MA: MIT Press.

Guth, James L., John C. Green, Lyman A. Kellstedt, and Corwin W. Smidt. 1995. "Faith and the Environment: Religious Beliefs and Attitudes on Environmental Policy." American Journal of Political Science 39(2):364-82.

Hershey, Marjorie Randon, and David B. Hill. 1977-1978. "Is Pollution 'a White Thing'? Racial Differences in Preadults' Attitudes." Public Opinion Quarterly 41(4): 439-58.

Hetherington, Marc J. 2004. Why Trust Matters: Declining Political Trust and the Demise of American Liberalism. Princeton, NJ: Princeton University Press.

Johnson, Martin, Paul Brace, and Kevin Arceneaux. 2005. "Public Opinion and Dynamic Representation in the American States: The Case of Environmental Attitudes." Social Science Quarterly 86(1):87-108.

Jones, Robert Emmet, and Lewis F. Carter. 1994. "Concern for the Environment Among Black Americans: An Assessment of Common Assumptions." Social Science Quarterly 75(3):560-79.

Kanagy, Conrad L., Craig R. Humphrey, and Glenn Firebaugh. 1994. "Surging Environmentalism: Changing Public Opinion or Changing Publics." Social Science Quarterly 75:804-19.

Klineberg, Stephen L., Matthew McKeever, and Bert Rothenbach. 1998. "Demographic Predictors of Environmental Concern: It Does Make a Difference How it's Measured." Social Science Quarterly 79(4):734-53.

Mohai, Paul. 1992. "Men, Women, and the Environment: An Examination of the Gender Gap in Environmental Concern and Activism." Society and Natural Resources 5(1): $1-19$.

Mohai, Paul, and Bunyan Bryant. 1998. "Is There a 'Race' Effect on Concern for Environmental Quality?” Public Opinion Quarterly 62(4):475-500.

Murch, Arvin W. 1971. "Public Concern for Environmental Pollution." Public Opinion Quarterly 35:100-06.

Press, Daniel. 2003. "Who Votes for Natural Resources in California?" Society \& Natural Resources 16(9):835-46.

Rivers, Douglas. n.d. Representative Sample Matching from Internet Surveys. Available at $\langle$ http://web.mit.edu/polisci/portl/cces/material/sample_matching.pdf $\rangle$.

Scott, David, and Fern K. Willits. 1994. "Environmental Attitudes and Behavior: A Pennsylvania Survey." Environment and Behavior 26(2):239-60. 
Uyeki, Eugene, and Lani Holland. 2000. "Diffusion of Pro-Environmental Attitudes?" American Behavioral Scientist 43(4):646-62.

Van Liere, Kent D., and Riley E. Dunlap. 1980. "The Social Bases of Environmental Concern: A Review of the Hypotheses, Explanations, and Empirical Evidence." Public Opinion Quarterly 44(2):181-97.

_. 1981. "Environmental Concern: Does it Make a Difference How it's Measured?" Environment and Behavior 13(6):651-76.

Xiao, Chenyang, and Riley E. Dunlap. 2007. "Validating a Comprehensive Model of Environmental Concern Cross-Nationally: A U.S.-Canadian Comparison." Social Science Quarterly 88(2):71-93. 